\title{
The Burden of Metastatic Lymphadenopathy in Jammu Region - An Observational Study
}

\author{
Aishvarya Jandial ${ }^{1}$, Surbhi Mahajan ${ }^{2}$, Subhash Bhardwaj ${ }^{3}$, Akhil Mahajan ${ }^{4}$ \\ ${ }^{1,2,3}$ Department of Pathology, ${ }^{4}$ Department of Medicine; \\ Government Medical College, Jammu University, Jammu, India
}

Corresponding Author: Aishvarya Jandial

DOI: https://doi.org/10.52403/ijrr.20220140

\begin{abstract}
Background: Lymphadenopathy may be the first sign of malignancy and use of FNA in the diagnosis of metastatic disease is well established. In patients with enlarged lymph nodes and previously documented malignancy, FNAC can obviate further surgery performed merely to confirm the presence of metastasis.

Aim: The objective was to study the relative frequency of various metastatic lymph node lesions in hospital based population in Jammu region.

Material and Methods: In this study, we analysed the clinicopathological features of metastatic lymphadenopathy, diagnosed on FNAC in the Jammu region of Jammu and Kashmir Union Territory of India over a period of three years.

Interpretation and Results: A total of 190 lymph nodes were labelled as metastatic on FNAC. The age of the patients ranged from 12 to 95 years, with maximum number of cases in 51-60 years age group. Male predominance was seen with a male: female ratio of 2.3:1. The cervical lymph nodes were involved most commonly $(48.42 \%)$. The most common metastatic malignancy reported was squamous cell carcinoma (115 cases, $60.50 \%)$ with oral cavity being the most common primary site of malignancy.

Conclusion: In the present study FNAC proved to be a useful diagnostic modality in the diagnosis of metastatic malignancies due to its rapidity of diagnosis, ease of performance and minimal complications.
\end{abstract}

Keywords: Fine needle aspiration cytology, FNAC, Jammu, Lymphadenopathy, Metastatic.

\section{INTRODUCTION}

Lymphadenopathy can be caused by proliferation of cells intrinsic to the node, such as lymphocytes, plasma cells, monocytes or histiocytes or infiltration of cells extrinsic to the node such as neutrophils and malignant cells. Lymph nodes get enlarged due to non-neoplastic and neoplastic conditions. Non neoplastic conditions include infections like tuberculosis, AIDS, acute and chronic nonspecific lymphadenitis, dermatopathic lymphadenitis and chronic granulomatous diseases like sarcoidosis and in diseases like Castleman disease, Rosai-Dorfman disease and Kimura's disease. Neoplastic conditions include primary and secondary lymph nodal malignancies. Lymphadenopathy is classified as "generalized" if lymph nodes are enlarged in two or more non-contiguous areas and "localised" if only one area is involved. It can be either acute or chronic. In acute condition, the nodes are enlarged and tender along with various constitutional symptoms like fever, malaise, local pain and tenderness whereas in chronic variety the nodes are usually painless and nontender with delayed development of constitutional symptoms (1). To diagnose the cause of lymphadenopathy, medical history like the presence of B symptoms (fever, night sweats, unexplained weight loss $>10 \%$ over 6 months) and other symptoms like fatigue, pruritus are quite helpful in reaching towards a diagnosis. Along with medical history different diagnostic modalities being 
used are computed tomography (CT), magnetic resonance imaging (MRI), fine needle aspiration cytology (FNAC) and image guided core needle biopsy (2). Among these FNAC is cheaper, safer, cost effective and faster technique with a high degree of accuracy. Any malignant tumour can give rise to lymph node metastases, but the incidence varies greatly depending on the tumour type. Malignancies in lymph nodes in India are predominantly metastatic with incidence ranging from $65.7 \%$ to $80.4 \%$ (3). FNAC of superficial lymph nodes can be done directly and from deeply seated nodes with the help of radiological guidance. FNAB, in conjunction with ultrasound guidance is currently the first line ancillary method for evaluation and diagnosis of head and neck masses of all types. Ultrasound guided FNA has been described for cancer of head and neck with sensitivity and specificity of over $90 \%$ (4). It is also an effective way of identifying and sampling non palpable malignant supraclavicular nodes in patients with lung cancer. Supraclavicular lymph node enlargement can sometimes become difficult to be detected on clinical examination but sonographically the nodes can be detected easily as malignant nodes become rounded with increased short axis diameter and develop a heterogenous echo texture. Axillary lymph node metastasis is an important prognostic factor in early stage breast cancer and remains crucial for individual treatment decisions. Ultrasound guided FNA of axillary lymph nodes can reliably predict the presence of metastasis and refer these patients for appropriate surgical treatment, thus avoiding sentinel lymph node biopsy (5). This procedure has been conducted in several institutions reporting a sensitivity, specificity, positive predictive value (PPV) and negative predictive value (NPV) of $86.4 \%, 100 \%$, $100 \%$ and $67 \%$ respectively, with an accuracy of $79 \%$ Kapila (6). Endoscopic ultrasound guided FNA (EUS-FNA) has proven to be helpful in obtaining tissue samples from enlarged mediastinal and intraabdominal lymph nodes. It is especially beneficial in the diagnosis and staging of malignancy. Therefore, FNAB material is valuable not only for diagnostic but also for prognostic and therapeutic purposes. Lymphadenopathy may be the first sign of malignancy and use of FNA in the diagnosis of metastatic disease is well established (7). In patients with enlarged lymph nodes and previously documented malignancy, FNAC can obviate further surgery performed merely to confirm the presence of metastasis. FNAC helps in confirming or excluding malignancy, particularly metastatic disease with a known history of malignancy. It is useful for detection of recurrence and new metastasis. It may be the first investigation to clinch a diagnosis of occult malignancy (8). The diagnosis of metastatic tumour to the lymph node on cytological smear is crucial and highly reliable. However, in most of these cases, the primary tumour is clinically known and FNAC is used widely for the follow up of these patients. Most of metastatic carcinoma can be identified by their cytomorphological characteristics alone. Sensitivity and positive predictive value of cytological diagnosis were calculated to be $100 \%$ and 93.1\% respectively (9). However, FNAC helps to avoid additional surgical procedures insubstantial number of patients. It allays tension and anxiety of surgical procedures. Thus, FNAC may serve as a triaging modality in the selection of those patients who can undergo clinical follow up and those requiring a surgical biopsy (10).

\section{MATERIAL AND METHODS}

This is a 3 years observational study carried out in the department of Pathology, Government Medical College Jammu from 1-10-2018 to 31-10-2021, after getting valid, informed consent from patients and after getting permission from the institutional ethics committee. It includes 150 cases of lymphadenopathy, diagnosed as metastatic on FNAC. Informed and written consent was obtained. After taking all aseptic precautions FNAC was carried 
out using a 22-24 gauze disposable needle and $10 \mathrm{ml}$ syringe. Slides were stained with May Grunwald Giemsa (dry fixation) and Papanicolaou stain (wet fixation). A thorough relevant history was taken along with complete local examination of the palpable lymph nodes and their location, size, consistency was noted. For superficial lymphadenopathy, direct fine needle aspiration was performed and for deep seated lymphadenopathy like those in retroperitoneum or in the mediastinum, ultrasound guided or CT guided FNAC was performed.

\section{Inclusion Criteria:}

1. All patients of lymphadenopathy diagnosed as metastatic on cytology.

\section{Exclusion Criteria:}

1. All the cases of benign lymphadenopathy.

2. All cases of primary lymphoidal malignancies diagnosed on cytology.

3. Cases with inadequate smears and which were not optimally preserved.

4. Abnormal coagulation profile in case of image guided FNAC.

\section{RESULTS}

Of all lymph nodes that were aspirated, 190 cases were reported as metastatic. There were 132 males $(69.50 \%)$ and 58 females $(30.50 \%)$ with a male to female ratio of 2.3:1. The age of the patients ranged from 12 to 95 years with a mean age of 53.5 years. Majority of patients 60 patients $(31.57 \%)$ were in the age group of 51-60years followed by 45 patients (23.68\%) patients in the age group of 61-70 years. The most commonly involved lymph node was the cervical group of lymph nodes in 92 patients $(48.42 \%)$, followed by supraclavicular in 34 patients (17.89\%), submandibular 33 patients (17.36\%), posterior triangle 10 patients $(5.26 \%)$, axillary 7 patients $(3.68 \%)$, inguinal 6 patients $(3.15 \%)$, preauricular and infraauricular 3 patients (1.60\%) each, post auricular and retroperitoneal 1 patient each $(0.52 \%)$
Out of 190 cases of metastatic malignancies, squamous cell carcinoma was the most commonly diagnosed metastatic malignancy and was seen in 115 patients $(60.5 \%)$ followed by poorly differentiated carcinoma in 39 patients $(20.55 \%)$ adenocarcinoma in 29 patients $(15.30 \%)$, small cell carcinoma in 2 patients $(1.05 \%)$, malignant melanoma, nasopharyngeal carcinoma, olfactory neuroblastoma, renal cell carcinoma and rhabdomyosarcoma in 1 patient $(0.52 \%)$ each. The most common site of primary malignancy was the oral cavity, followed by larynx, hypopharynx and oropharynx. In females, apart from these, primary in the breast was also common.

Table I:- Age wise distribution of patients

\begin{tabular}{|c|c|c|}
\hline Age (years) & Frequency & Percentage (\%) \\
\hline $11-20$ & 6 & $3.15 \%$ \\
\hline $21-30$ & 13 & $6.84 \%$ \\
\hline $31-40$ & 14 & $7.36 \%$ \\
\hline $41-50$ & 38 & $20 \%$ \\
\hline $51-60$ & 60 & $31.57 \%$ \\
\hline $61-70$ & 45 & $23.68 \%$ \\
\hline $71-80$ & 10 & $5.26 \%$ \\
\hline$>80$ & 4 & $2.10 \%$ \\
\hline
\end{tabular}

Table II:- Distribution of metastatic malignancies in patients

\begin{tabular}{|c|c|c|}
\hline Metastatic malignancy & Frequency & Percentage \\
\hline Metastatic Squamous cell carcinoma & 115 & $60.50 \%$ \\
\hline $\begin{array}{lll}\begin{array}{l}\text { Metastatic } \\
\text { carcinoma }\end{array} & \text { Poorly } & \text { differentiated } \\
\end{array}$ & 39 & $20.55 \%$ \\
\hline Metastatic Adenocarcinoma & 29 & $15.30 \%$ \\
\hline Metastatic Small cell carcinoma & 2 & $1.05 \%$ \\
\hline Metastatic Malignant melanoma & 1 & $0.52 \%$ \\
\hline $\begin{array}{ll}\begin{array}{l}\text { Metastatic } \\
\text { carcinoma }\end{array} & \text { Nasopharyngeal } \\
\end{array}$ & 1 & $0.52 \%$ \\
\hline Metastatic Olfactory neuroblastoma & 1 & $0.52 \%$ \\
\hline Metastatic Renal cell carcinoma & 1 & $0.52 \%$ \\
\hline Metastatic Rhabdomyosarcoma & 1 & $0.52 \%$ \\
\hline Total & 190 & $100 \%$ \\
\hline
\end{tabular}

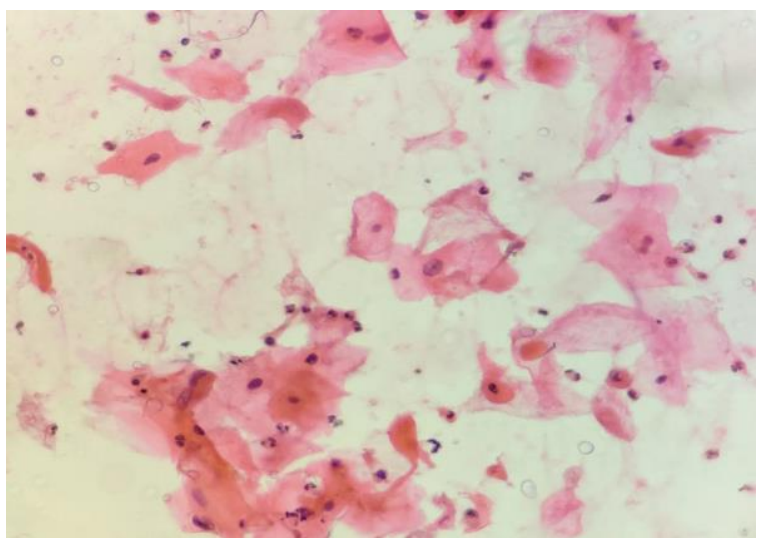

FigI: FNA smears from cervical lymph node aspirate showing metastatic deposits of Well differentiated squamous cell carcinoma (Pap 400x). 


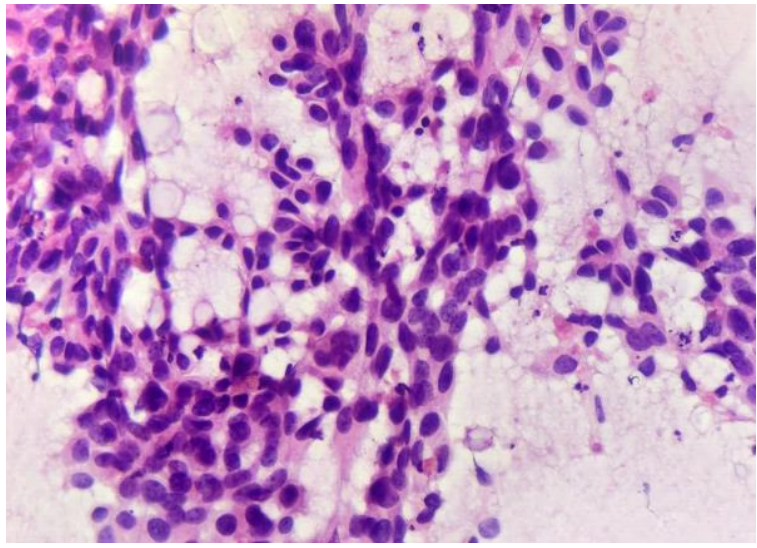

Fig. II: FNA smears from cervical lymph node aspirate showing metastatic deposits of adenocarcinoma in a $\mathrm{K} / \mathrm{C} / \mathrm{O}$ Breast carcinoma (Pap 400x).

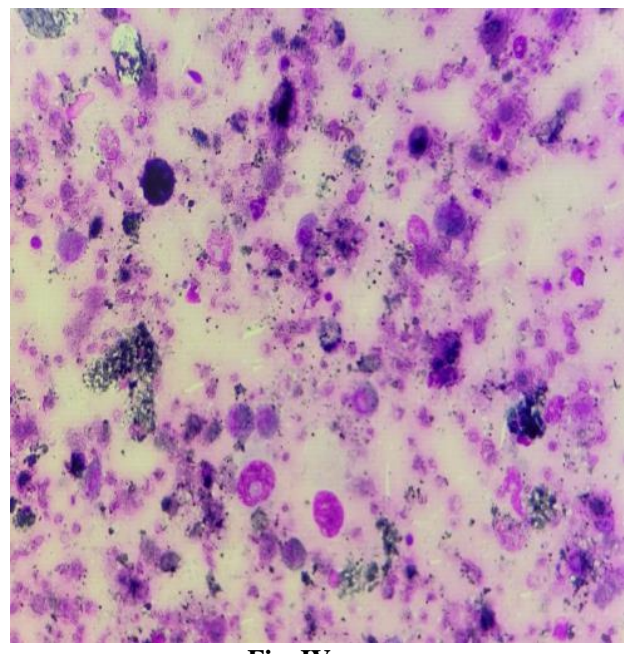

Fig. IV

Fig. IV: FNA smears from axillary lymph node showing metastatic deposits of malignant melanoma (MGG 400x) Fig V: FNA smears from supraclavicular lymph node showing metastatic deposits of renal cell carcinoma (MGG 400X).

\section{DISCUSSION}

The burden of primary and secondary lymph nodal malignancy is rising worldwide as well as in India. Symptoms and signs, although indicative of etiology, are not a substitute for morphological diagnosis. So, here FNA acts as a valuable tool which saves a lot of time and enables the clinician to plan the treatment accordingly (11). The present study was carried out to quantify these metastatic malignancies and to describe the cytomorphological features by using FNAC. FNAC offers various advantages. It is minimally invasive, produces a speedy result and is inexpensive (12). The main importance of FNAC is that, this simple diagnostic procedure can be easily performed in any peripheral center with minimal resources. The set up does not

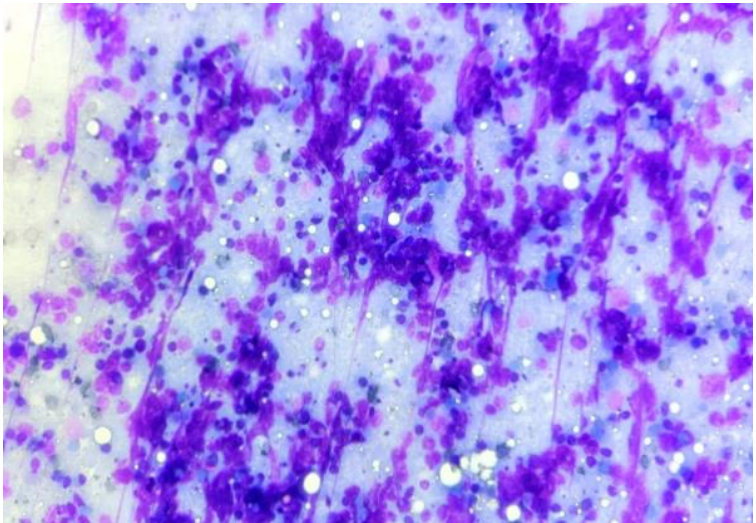

Fig. III: FNA smears from supraclavicular lymph node showing metastatic deposits of small cell carcinoma. K/C/O small cell carcinoma, Lung (MGG 400x)

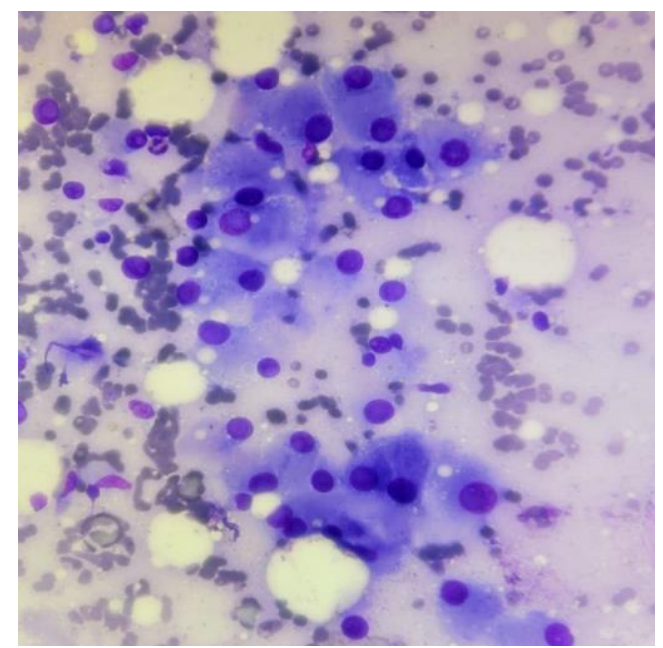

Fig. $\mathrm{V}$

require any sophisticated machinery and can be performed in day care settings. This way majority of cases can be easily managed on FNAC (13). The present study included 190 cases who presented with lymphadenopathy, had undergone FNAC and were labelled as metastatic. The study was conducted to analyse the clinico-pathological features of metastatic lesions of peripheral lymph nodes for various malignant tumors and for confirmation of metastatic lesions in case of known or an occult primary. The age of the patients ranged from 12-95 years which was comparable to studies carried out by Sravani $P$ et al (14) and Chakravarty-Vartak US et al (1). In our study, males constituted the predominant population which is similar to studies carried out by Vimal $S$ et al (15) and Patel MM et al (16). Males presenting with metastatic lesions can be attributed to 
the use of tobacco, alcohol, cigarette smoking etc. In our study majority of patients were in the age group of 51-60 years followed by patients in the age group of 61-70 years which is similar to other studies carried out by Khurajidam SD et al (17) and Patro $P$ et al (18) in the literature. However, with the increase in the consumption of tobacco, paan, areca nut, alcohol etc, the younger age group is also being affected. Cervical lymph node was the most commonly involved lymph node in 92 cases $(48.50 \%)$ followed by supraclavicular lymph nodes 34 cases $(18.00 \%)$. These findings were similar to study conducted by Rathod KM et al (19), Patro $P$ et al (18) and Batni $G$ et al (4). Out of 190 cases of metastatic malignancies, squamous cell carcinoma was the most commonly diagnosed metastatic malignancy and was seen in 115 patients $(60.50 \%)$ followed by poorly differentiated carcinoma in 39 patients $(20.55 \%)$ and adenocarcinoma in 29patients $(15.28 \%)$ which was similar to studies conducted by Singh A et al (20), Arundhati et al (6) and Wilkinson AR et al (21). Out of 190 patients of metastatic malignancies, 35 patients were known cases of carcinoma of oral cavity, 1 female patient was a known case of breast carcinoma and 1 patient had a history of lung carcinoma, small cell type, rest all had no history of primary malignancy.

\section{CONCLUSION}

Cytological evaluation along with proper clinical correlation is quite useful in diagnosing metastasis with good degree of certainty. In the present study FNAC proved to be a useful diagnostic modality in the diagnosis of metastatic malignancies due to its rapidity of diagnosis, ease of performance and minimal complications.

Acknowledgement: None

Conflict of Interest: None

Source of Funding: None

Ethical Approval: Approved

\section{REFERENCES}

1. Chakravarty-Vartak US, Vartak SS, Nichat PB. Metastatic lymphadenopathy by fine needle aspiration cytology. Int J Sci Stud 2016;4(3):192-196

2. Dowerah S, Kouli R, Karmakar T. A study of FNA findings of malignancy in lymph nodes with special emphasis on metastatic lymphadenopathy. Int J Basic Med Sci 2014; 5(4)530-533

3. Fernández Aceñero MJ, Caso Viesca A, Díaz del Arco C. Role of fine needle aspiration cytology in the management of supraclavicular lymph node metastasis: Review of our experience. Diagn Cytopathol 2018;3:1-6

4. Batni G, Gaur S, Sinha O.N., Agrawal SP, Srivastava A.A Clinico-Pathological Study of Cervical Lymph Nodes. Indian $J$ Otolaryngol Head Neck Surg (Oct-Dec 2016) 68(4):508-510.

5. Rai NN, Patangia P, Meena SP.Role of fine needle aspiration cytology in diagnosis of metastatic lymphadenopathy. J. Evid. Based Healthc. 2016;3(18):738-741

6. Arundhati, Jha PC. Fine needle aspiration cytology in metastatic lymph nodes: A study from Bihar. Ann Int Med Den Res. 2017; 3(4):28-30

7. Rathod DG, Singla DD. Our experience of metastatic lesion of lymph node diagnosed by fine needle aspiration cytology. NJIRM. 2015;6(5):34-7

8. Manupriya S, Aruna G, Kaul R. Utility of FNAC in Diagnosis of Lymph Node Malignancies: An Audit from a Rural Medical College. Int J Cancer Cell Biol Res. 2017; 2(2): 034-038

9. Mehdi G, Singh AK, Hasan M, Ansari HA, Rehman S, Mirza S, et al. Cytological evaluation of enlarged lymph nodes in metastatic disease: A hospital-based assessment. Clin Cancer Invest J 2015;4: 152-157

10. Mehmood S, Loya A, Yusuf MA. Clinical utility of endoscopic ultrasound- guided fine needle aspiration in the diagnosis of mediastinal and intraabdominal lymphadenopathy. Acta Cytol 2013;57:436442

11. Pusztaszeri MP, Faquin WC. Cytologic evaluation of cervical lymph node metastases from cancers of unknown primary origin. Diagn Cytopathol 2015;32: $31-41$ 
12. Qadri SK, Hamdani NH, Shah P, Khalil MB. Metastatic lymphadenopathy in Kashmir Valley: A clinicopathological study. Asian Pac J cancer Prev. 2014;15 (1):419-422

13. Rai NN, Patangia P, Meena SP. Role of fine needle aspiration cytology in diagnosis of metastatic lymphadenopathy. J. Evid. Based Healthc. 2016;3(18):738-741

14. Sravani P, Neerja M, Bhavani C. Fine needle aspiration: a simple and handy tool to diagnose malignant lymphadenopathy. Int J Res Med Sci 2017;5:3949-53

15. Vimal S, Dharwadkar A, Chandanwale SS, Vishwanathan V, Kumar H. Cytomorphological study of lymph node lesions: A study of 187 cases. Med J DY Patil Univ 2016;9:43-50

16. Patel MM, Italiya SL, Dhandha ZB, Dudhat RB, Kaptan KR, Shah MB et al. Study of metastasis in lymph node by fine needle aspiration cytology: our institutional experience. Int J Res MedSci 2013;1:451-4

17. Khurajidam SD, Sarkar R, Haldar B, Rasaily N, Khurijidam S, Debnath K. Aspiration cytology of metastatic neck node: A 5-year study. J Med Soc 2015;29: 160-163

18. Patro P, Lad P, Hoogar MB. Spectrum of lesions in lymph nodes- a cytological study. Int J Health Sci Res. 2018; 8(11):75-81

19. Rathod KM, Shah SA. A study of metastatic lesion of lymph node by fine needle aspiration cytology. Natl J Community Med 2012;3(4):708-710

20. Singh A, Bhambani P, Nema SK.Diagnostic accuracy of FNAC in diagnosis for causes of lymphadenopathy: a hospital based analysis. Int J Res Med Sci 2013;1:271-77

21. Wilkinson AR, Mahore SD, Maimoon SA. FNAC in the diagnosis of lymph node malignancies: A simple and sensitive tool. Indian J Med Paediatr Oncol 2012;33:2124.

How to cite this article: Jandial A, Mahajan S, Bhardwaj $S$ et.al. The burden of metastatic lymphadenopathy in Jammu region-an observational study. International Journal of Research and Review. 2022; 9(1): 334-339. DOI: https://doi.org/10.52403/ijrr.20220140 